\title{
Overexpression of BrTSR53 Gene Improves Tolerance of Rice Plant to Salt Stress
}

\author{
A-Ram Kim ${ }^{\dagger}$, Hyemin Lim ${ }^{\dagger}$, Jung-Il Cho, Chang-Kug Kim, Seung Uk Ji, Soo-Chul Park, Gang-Seob Lee* \\ Department of Agricultural Biotechnology, National Academy of Agricultural Science, Jeonju, 54874, Korea
}

\begin{abstract}
Plant is frequently exposed to various abiotic stress. Salt stress is particularly an important abiotic stress that seriously affects plant growth and development. BrTSR53 gene, a putative stress-related gene isolated from Brassica rapa, was used to generate overexpression transgenic rice. The over-expression of BrTSR53 in BrTSR53-OX transgenic rice was confirmed by quantitative RT-PCR and western blot analysis. To elucidate the role of BrTSR53 in stress tolerance, responses of BrTSR53-OX transgenic rice plants to salt stress conditions were examined. BrTSR53-OX \#12, \#28, and \#32 lines were treated with salt stress on MS medium containing $100 \mathrm{mM}$ or $200 \mathrm{mM}$ of $\mathrm{NaCl}$ for 5 and 14 days. Morphological analysis revealed differences between the three transgenic BrTSR53-OX rice and the wild-type rice. The germination rates of the three transgenic BrTSR53-OX lines of rice were significantly higher than that of the wild type rice, indicating that they were more tolerant to $200 \mathrm{mM} \mathrm{NaCl}$ than the wild type rice. In addition, the three transgenic BrTSR53-OX rice lines had significantly longer length of root and shoot compared to the wild type rice. These results suggest that the BrTSR53 gene played an important role in the tolerance of rice to salt stress. Therefore, it might be a potential target for the purpose of improving salt tolerance of rice and other crops.
\end{abstract}

Keywords Brassica rapa, BrTSR53 gene, Salt stress, Transgenic rice

\section{INTRODUCTION}

Abiotic stress in plants is likely to be increased due to climate changes. To increase crop cultivation, it is important and necessary to develop stress resistant crops (Kathuria et al. 2007). Salt stress is particularly an important factor that limits the growth and productivity of crops. Recently, there has been an increase in cases of crops suffering salt damage, accounting for approximatley $20 \%$ of global agricultural production (Zhu 2001). Saline soil can reduce crop productivity by increasing the concentration of $\mathrm{Na}^{+}$ and $\mathrm{Cl}^{-}$ions in leaves. These ions also can impair cell growth and photosynthesis. They ultimately act as cytotoxins, promote leaf aging, and interfere with carbon fixation and the formation of reproductive organs (Zhu 2001).

Plants possess numerous mechanisms to adapt to physiological, morphological, and biomolecular changes caused by stress (Yu et al. 2013). Genes induced by stress generate important functional proteins, which in turn can regulate genes involved in cell protection and signal transduction during stress response (Nakashima et al. 2007). To study abiotic stress-responsive mechanism in Brassica species, a number of Brassica rapa samples have been used to analyze the transcriptome of abiotic stress-treated B. rapa using oligo microarray (Lee et al. 2008). Transcription factors are important regulators of gene expression and abiotic-stress responses. It has been demonstrated that plant stress resistance can be improved by inducing the expression of stress-related target genes (Ravikumar et al. 2014). Over-expression of genes in transgenic plants has been shown to be able to enhance tolerance of plants to various abiotic stresses (Dubouzet $e t$ al. 2003; Nakasima et al. 2007; Xiang et al. 2008).

Rice is one of the most important food crops in the world. It is very sensitive to salinity and water stress. The growth

Received November 16, 2015; Revised November 19, 2015; Accepted November 20, 2015; Published November 30 , 2015

*Comesponding author Gang-Seob Lee, kangslee@korea.kr, Tel: +82-63-238-4714, Fax: +82-63-238-4704

${ }^{\dagger}$ These authors contributed equally to this work. 
and productivity of rice are frequently affected by various environmental factors. Such us, although it is well known that rice is very sensitive to salt stress, genes that could improve the salt tolerance of rice remain unclear. Therefore, we report the isolation of a putative stress-related gene BrTSR53 induced under salt stress condition from Brassica rapa. The responses of 35S::BrTSR53 over-expression transgenic rice plant to salt stress condition were examined.

\section{MATERIALS AND METHODS}

\section{Plant materials and growth conditions}

Rice (Oryza sativa L. cv. Dongjin) was used in this study. Rice seeds were sterilized in $70 \%$ ethanol and $2 \%$ $\mathrm{NaClO}$. Sterilized seeds were allowed to germinate at $28^{\circ} \mathrm{C}$ in a growth chamber. Two-week-old seedlings were transferred to soil culture in a green house with a dark/light cycle of $8 / 16 \mathrm{~h}$ at $28^{\circ} \mathrm{C}$. All tissue samples collected were immediately frozen in liquid nitrogen and stored at $-70^{\circ} \mathrm{C}$.

\section{Construction of $35 S:$ BrTSR53 expression vector}

The full-length cDNA of BrTSR53 (BRAS0001S00024153) gene from Brassica rapa was amplified by RT-PCR. Myc-tag was added to primer site of the coding region. The following primers were used: BrTSR53-OX F 5'-TCTAGA ATGGAACAAAAACTCATCTCAGAAGAAGATCTT ATGACTTCATGGAAGAAAAC-3' containing $X b a \mathrm{I}$ and myc-tag, and BrTSR53-OX R 5'-GGATCC TTAAGAAGACAGATTGTTTG-3' containing BamHI. BrTSR53-OX under the control of CaMV $35 \mathrm{~S}$ promoter and pinII terminator in PPZP vector was used in PCR to generate expression vector 35S::BrTSR53.

\section{Generation of transgenic rice plants}

To generate transgenic rice plants, Agrobacterium tumefaciens LBA4404 was transformed with 35S::BrTSR53 vector using freeze-thaw method. Rice transformation was performed using method described by Hiei et al. (1994) and Toki et al. (2006). Transgenic rice plants were regenerated from transformed calli using selection medium containing $4 \mathrm{mg} / \mathrm{L}$ phosphinothricin and $250 \mathrm{mg} / \mathrm{L}$ cefotaxime.

\section{Genomic DNA extraction and TaqMan copy number analysis}

Genomic DNAs of transgenic plants were extracted using Inclone ${ }^{\mathrm{TM}}$ genomic DNA prep kit (Inclone, Korea). Bar gene selection of transgenic plants was performed using PCR with the following primers: Bar-F 5'-ATGAGCCCAGAACGACGCCCG-3', Bar-R 5'-GATCTCGGTGACGGGCAGGA-3'. PCR reaction conditions included an initial denaturation at $95^{\circ} \mathrm{C}$ for $5 \mathrm{~min}$, followed by 35 cycles of denaturation for $30 \mathrm{sec}$ at $95^{\circ} \mathrm{C}$, annealing for $30 \mathrm{sec}$ at $56^{\circ} \mathrm{C}$, extension for $1 \mathrm{~min}$ at $72^{\circ} \mathrm{C}$, and $7 \mathrm{~min}$ extension at $72^{\circ} \mathrm{C}$.

Copy number of the transgene is an important standard to determine the utility of transgenic plants. Multi copies of transgene can result in co-suppression and gene silencing (Lowe et al. 2009). Copy number assay was performed on Applied Biosystems StepOnePlus ${ }^{\mathrm{TM}}$ (Applied Biosystems, Foster City, CA) with TaqMan ${ }^{\mathbb{R}}$ Gene Expression Master Mix (Applied Biosystems) kit. As an endogenous control, primers and probes of pre-designed TaqMan ${ }^{\circledR}$ copy number assay for rice tubulin alpha-1 chain gene (AK102560) were used. For the transgene, primers and probes were specifically designed for the terminator of nos gene. Primers used for the terminator of nos gene were: NOS-F (5'-GCATGACGTTATTTATGAGATGGGTTT-3'), NOS-R (5'-TGCGCGCTATATTTTGTTTTCTATCG-3'), and NOS-probe (5'-TAGAGTCCCGCAATTAT-3'). PCR amplifications were performed with the following parameters: enzyme activation at $95^{\circ} \mathrm{C}$ for $10 \mathrm{~min}$, followed by 40 cycles of denaturation for $15 \mathrm{sec}$ at $95^{\circ} \mathrm{C}$, annealing and extension for $1 \mathrm{~min}$ at $60^{\circ} \mathrm{C}$. To calculate the copy number of gene, relative quantitation analysis of genomic DNA targets was analyzed based on real-time PCR data using Applied Biosystems CopyCaller $^{\mathbb{R}}$ Software v2.0 (Applied Biosystems) according to the manufacturer's instructions.

\section{RNA extraction and quantitative real-time PCR}

Total RNA was extracted using RNeasy ${ }^{\circledR}$ Plant mini kit (QIAGEN, Germany) according to the manufacturer's protocol. cDNA synthesis was performed using amfiRivert Platinum cDNA synthesis master mix (GenDEPOT, 
Barker, TX). Quantitative real-time PCR (qRT-PCR) was performed on an Applied Biosystems StepOnePlus ${ }^{\mathrm{TM}}$ (Applied Biosystems) with SYBR ${ }^{\circledR}$ Premix Ex Taq ${ }^{\mathrm{TM}}$ (TaKaRa, Japan) kit. BrTSR53 gene expression in transgenic plants was determined by qRT-PCR with the following primers: BrTSR53-F 5'-GGTGACGTCATGGCTTGTGGCT-3', BrTSR53-R 5'-ACACGTGAAAAACGAG-AGGACAACA-3'. OsActin1 gene was used as internal control. OsActin1-F 5'-ACAGGTATTGTGTTGGACTCTGG-3' and OsActin1-R 5'-AGTAACCACGCTCCGTCAGG-3' were used for qRT-PCR with the following cycling parameters: $95^{\circ} \mathrm{C}$ for $30 \mathrm{sec}$ followed by 40 cycles at $95^{\circ} \mathrm{C}$ for $5 \mathrm{sec}$ and $60^{\circ} \mathrm{C}$ for $30 \mathrm{sec}$. Relative expression level was calculated using the comparative CT method (Livak and Schmittgen et al. 2001).

\section{Protein extraction and immunoblot analysis}

Total protein was extracted using method of MartinezGarcia et al. (1999). Protein expression was determined through western blot analysis. Total protein was separated by SDS-PAGE (stacking gel at 5\% and running gel at 12\%) and transferred to membranes. Anti-myc tag (Upstate, Billerica, MA) and anti-mouse IgG (Sigma, St. Louis, Missouri) were used as primary and secondary antibody, respectively. After washing membranes three times, immuno-reactive proteins were detected using Amersham ${ }^{\mathrm{TM}}$ ECL $^{\text {TM }}$ Prime Western Blotting Detection Reagent solution (Amersham Life Sciences, UK).

\section{Salt stress treatment to transgenic rice}

Salt stress treatment to transgenic rice was performed using method of Duan et al. (2012). Seeds of transgenic rice were sterilized in $70 \%$ ethanol and $2 \% \mathrm{NaClO}$. Sterilized rice seeds were transferred into 1/2 Murashige and Skoog (MS) liquid medium, 1/2 MS liquid medium containing $100 \mathrm{mM} \mathrm{NaCl}$, or $1 / 2 \mathrm{MS}$ liquid medium containing 200 $\mathrm{mM} \mathrm{NaCl}$. Seeds were incubated at $28^{\circ} \mathrm{C}$ for 5 days or 14 days. Shoot length, root length, and seed germination rate were recorded. All data from experiment of three times were analyzed by $t$-test analysis. Significantly different are indicate at $p<0.05\left(^{*}\right)$ and $p<0.01(* *)$.

\section{RESULTS}

\section{Production and analysis of BrTSR53-OX rice plants}

The BrTSR53 gene (putative Triple Stress Resistance53, BRAS0001S00024153) is categorized as an unknown gene in NCBI database. It has been reported that BrTSR53 is phylogenetically close to halophyte Eutrema salsugineum showing salt resistance in yeast cell (Kim et al. 2014). BrTSR53 gene isolated from Brassica rapa cDNA using RT-PCR was cloned into a pPZP vector, which included the CaMV 35S promoter, PinII terminator, and bar genes (Fig. 1A). A total of $32 \mathrm{T0}$ generation lines of BrTSR53-OX rice plants were generated. After extracting genomic DNAs from these 32 lines, PCR analysis was used to search for plants that possessed the bar gene (Fig. 1B). TaqMan copy number assay was used to select single-copy lines (Fig. 1C). BrTSR53-OX rice plant lines with T-DNA inserted in the intergenic region were selected by flanking sequence analysis. Eight lines of BrTSR53-OX rice plants with single-copy and an intergenic insertion were selected and separated to produce homozygous T2 generation. These single-copy/intergenic/homozygous BrTSR53-OX rice plants were used in subsequent experiments.

\section{Expression of the BrTSR53 gene in transgenic rice plants}

The transcriptional levels of the BrTSR53 gene in the eight lines of single-copy/intergenic/homozygous BrTSR53-OX rice plants were determined using qRT-PCR. Compared to BrTSR53-OX \#32, BrTSR53-OX \#17 showed higher level of expression. BrTSR53-OX \#10 showed a relatively low level of expression compared to other transgenic rice lines. However, it was 6-fold higher compared to BrTSR53-OX \#32 (Fig. 2A). In addition, the protein expression levels of BrTSR53 were determined by western blot analysis. BrTSR53 protein was detected in BrTSR53-OX lines at molecular weight of 10 to $15 \mathrm{kDa}$. However, this protein band was not detected in the wild-type rice plant. BrTSR53-OX \#12, \#28, and \#32 lines showed the highest expression of BrTSR53 protein (Fig. 2B). Therefore, these three lines were used in salt stress experiment. 
A

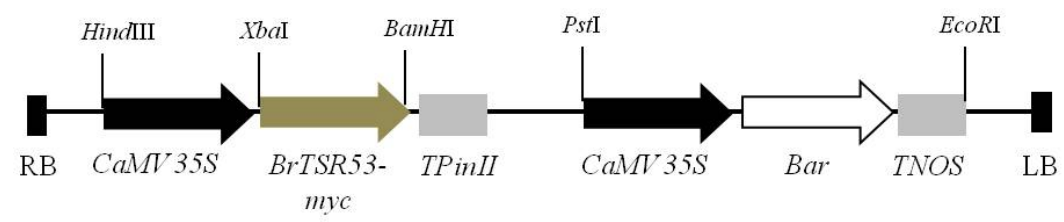

$\mathrm{B}$

\begin{tabular}{|c|c|c|c|c|c|c|c|c|c|}
\hline \multirow[b]{2}{*}{$\mathrm{M}$} & \multirow[b]{2}{*}{ P.C } & \multirow[b]{2}{*}{ N.C } & \multicolumn{6}{|c|}{ BrTSR53-OX } & \\
\hline & & & \#5 & $\# 6$ & $\# 10 \quad \# 12$ & \#17 & \#22 & \#28 & \#32 \\
\hline
\end{tabular}

C

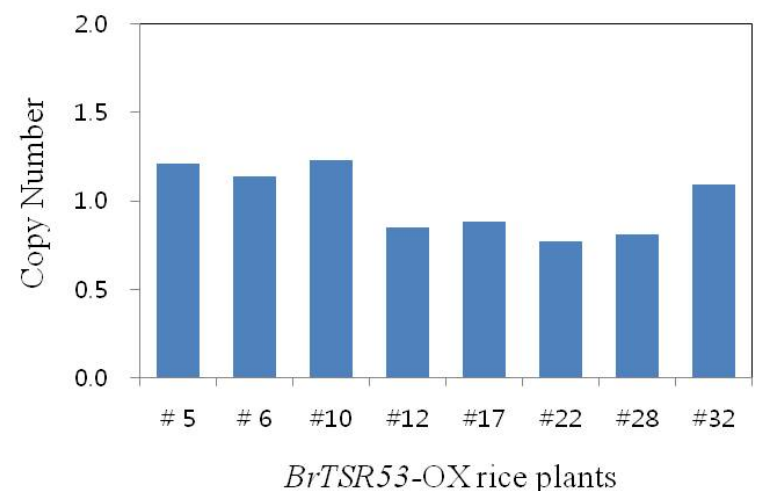

Fig. 1. BrTSR53-OX vector and molecular identification of transgenic rice. (A) Vector construction of 35S::BrTSR53-myc. RB: right border; LB: left border; CaMV 35S: cauliflower mosaic virus 35S promoter; TPinII: PinII terminater; TNOS: NOS terminater; Bar: selection marker. (B) DNA analysis by PCR. M: 1 kb DNA ladder; P.C: positive control; N.C: negative control. (C) Copy number assay by quantitative RT-PCR.

A

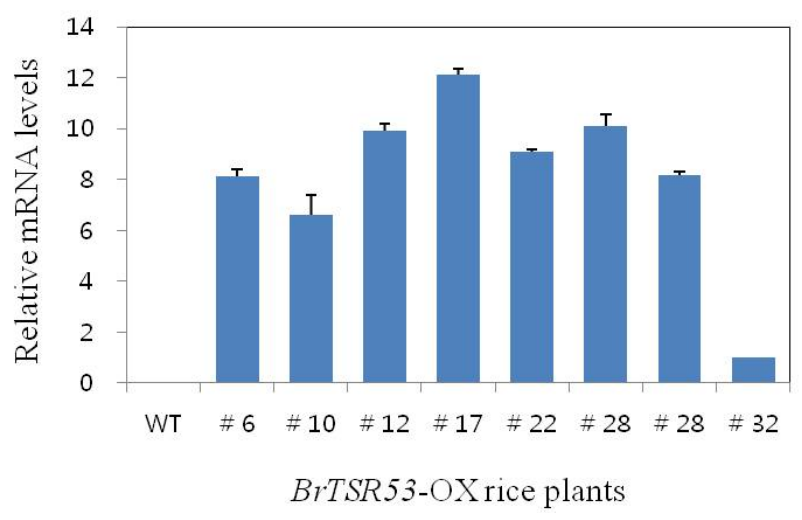

B

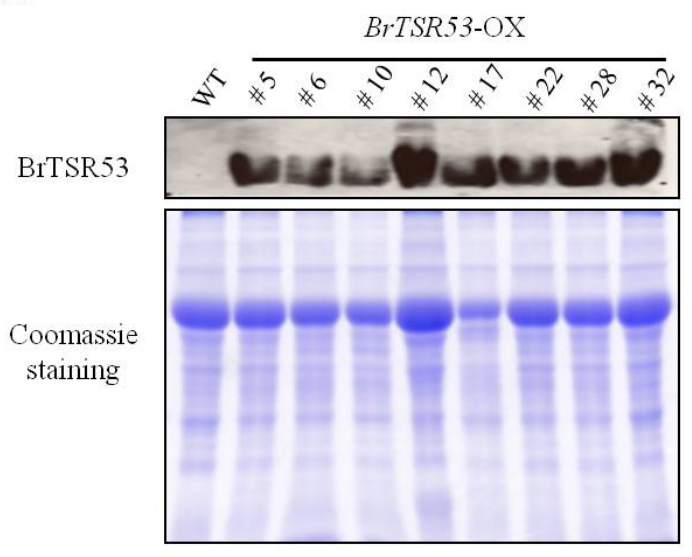

Fig. 2. Expression level of BrTSR53 gene or protein in BrTSR53-OX transgenic rice plants. (A) Expression of the BrTSR53 gene in transgenic rice by quantitative real time-PCR. OsActin was used as internal control. (B) BrTSR53 protein levels in transgenic rice plants based on western blot analysis. 


\section{BrTSR53-OX transgenic rice plants have enhanced tolerance to salt stress}

To examine the role of BrTSR53 in stress response of rice, seeds of BrTSR53-OX, BrTSR53-OX \#12, \#28, \#32, and wild-type rice plants were sown on MS agar plates containing different concentrations (100 and $200 \mathrm{mM}$ ) of $\mathrm{NaCl}$. Their germination rates and seedling growth were monitored. There was no significant $(p>0.05)$ difference between the wild-type rice plant and BrTSR53-OX rice plant cultured in MS medium without $\mathrm{NaCl}$ (Fig. 3). However, when they were cultured in MS medium containing $100 \mathrm{mM} \mathrm{NaCl}$ for 5 days, the BrTSR53-OX \#28 and \#32 rice lines showed different phenotype from that of the wild-type. Treatment with $200 \mathrm{mM} \mathrm{NaCl}$ inhibited the germination of wild-type rice plant. However, the germination of the three BrTSR53-OX lines of rice plants were not inhibited by the $200 \mathrm{mM} \mathrm{NaCl}$. With the treatment of $200 \mathrm{mM} \mathrm{NaCl}$, the germination of both BrTSR53-OX and wild-type seeds was inhibited the most. After 14 days of

A
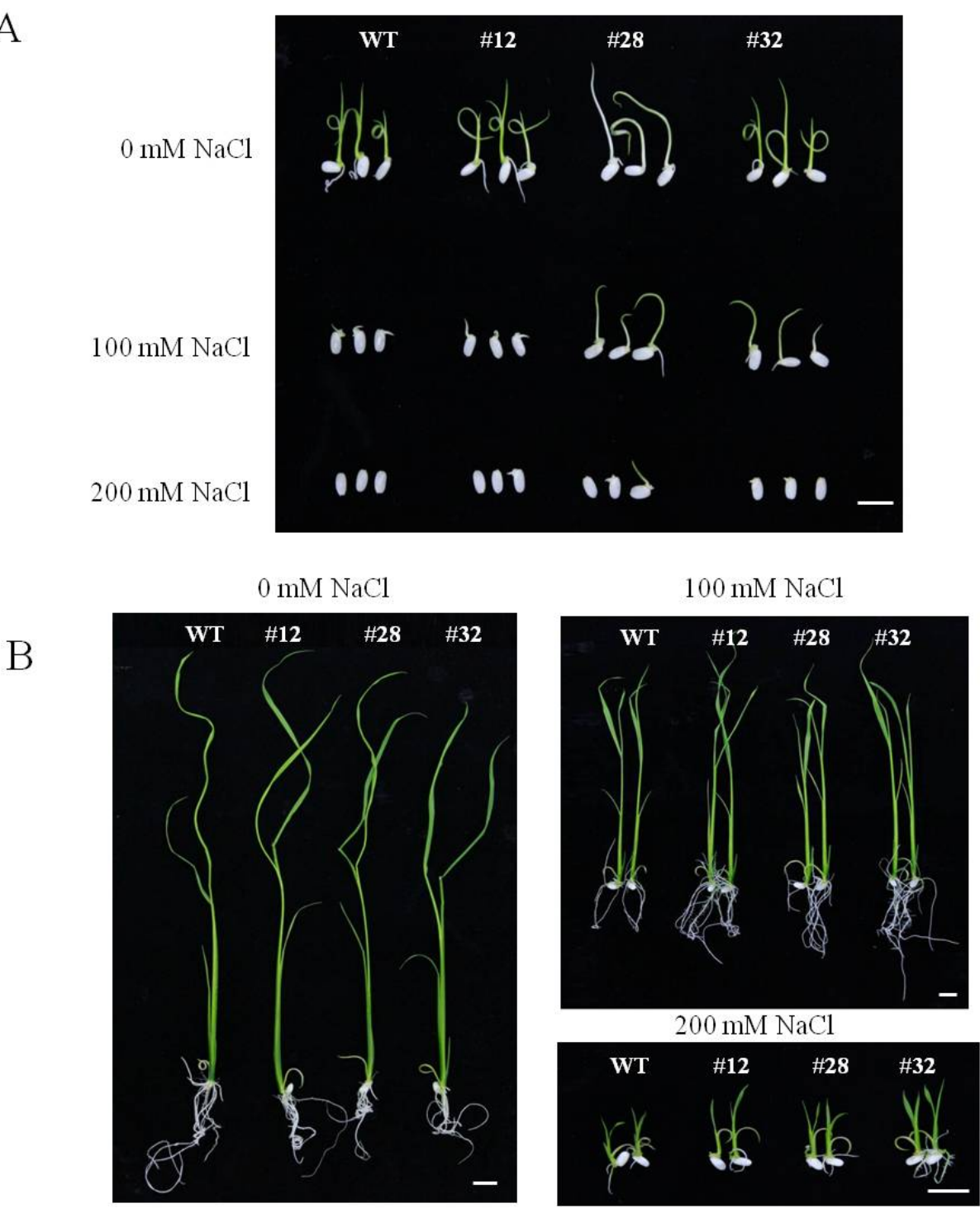

Fig. 3. Growth phenotype of BrTSR53-OX and wild-type rice plants under salt stress conditions. (A) Root and height of rice in MS medium containing $0 \mathrm{mM}, 100 \mathrm{mM}$, or $200 \mathrm{mM} \mathrm{NaCl}$ for 5 days. Bar: $1 \mathrm{~cm}$. (B) Root and height of rice in MS medium containing $0 \mathrm{mM}, 100 \mathrm{mM}$, or $200 \mathrm{mM} \mathrm{NaCl}$ for 14 days. Bar: $1 \mathrm{~cm}$. 
culture in MS medium containing $100 \mathrm{mM} \mathrm{NaCl}$, the germination rates of the wild-type and the BrTSR53-OX lines of rice seeds were $90 \%$ and $100 \%$, respectively. In MS medium containing $200 \mathrm{mM} \mathrm{NaCl}$, the germination rate of the wild-type rice seed was $30 \%$, while that of the BrTSR53-OX \#12, \#28, and \#32 was 70\%, 60\%, and 90\%, respectively (Fig. 4A). These results indicated that these lines were resistant to salt stress.

After 5 days of culture in MS medium, the shoot lengths of BrTSR53-OX lines plants were significantly $(p<0.05)$ longer than that of the wild-type (Fig. 4B). In MS medium containing $100 \mathrm{mM} \mathrm{NaCl}$, the shoot lengths of both BrTSR53-OX \#28 and \#32 were significantly $(p<0.01)$ longer than that of the wild-type. After 14 days of culturing in the MS medium, the shoot lengths and the root lengths of the three BrTSR53-OX lines were significantly $(p<0.05)$ longer than that of the wild-type. In MS media containing $200 \mathrm{mM} \mathrm{NaCl}$, the shoot and root lengths of BrTSR53-OX \#32 were significantly $(p<0.05)$ longer than that of the wild-type (Fig. 4C, D).

\section{DISCUSSION}

Plants have developed mechanisms to allow them rapidly respond to stresses in the environment. Expression of stress-related genes is primarily controlled by specific transcription factors such as MYB, bZIP, WRKY, AP2/ EREBP, LEA, and NAC (Zhong et al. 2012). According to Duan et al. (2012), the functions of LEA proteins include maintaining protein, sequestrating ions, and functioning as membrane structure or molecular chaperones to help prevent

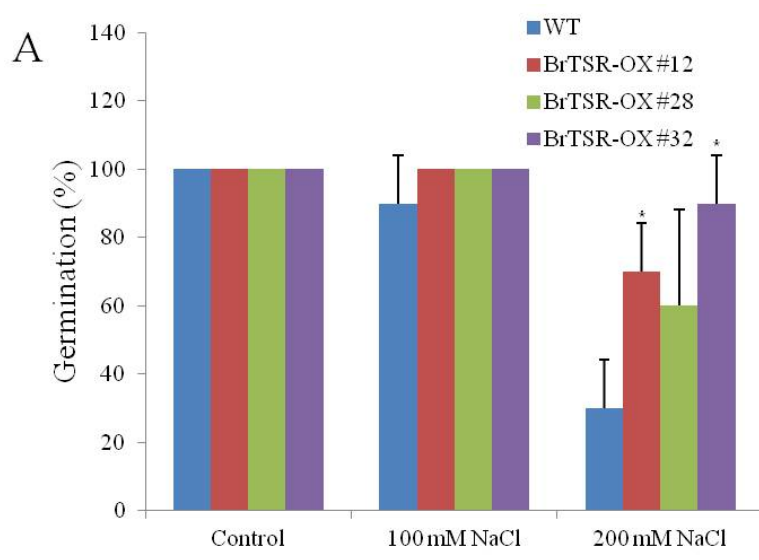

B

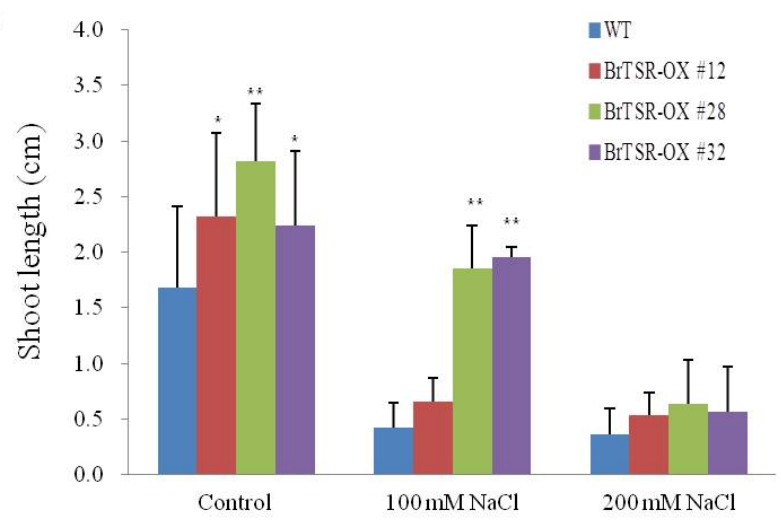

C

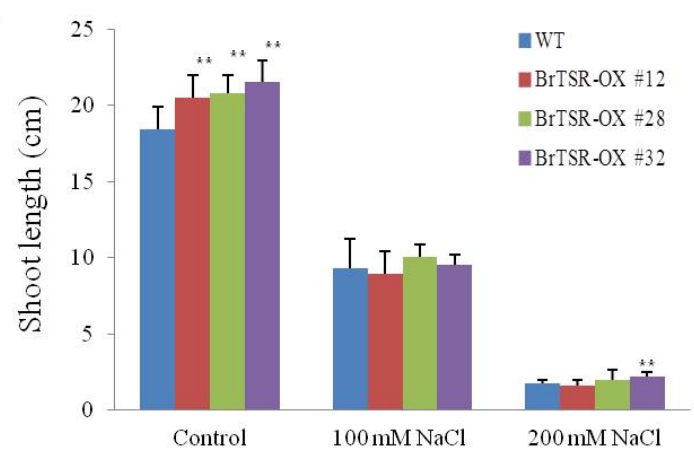

D

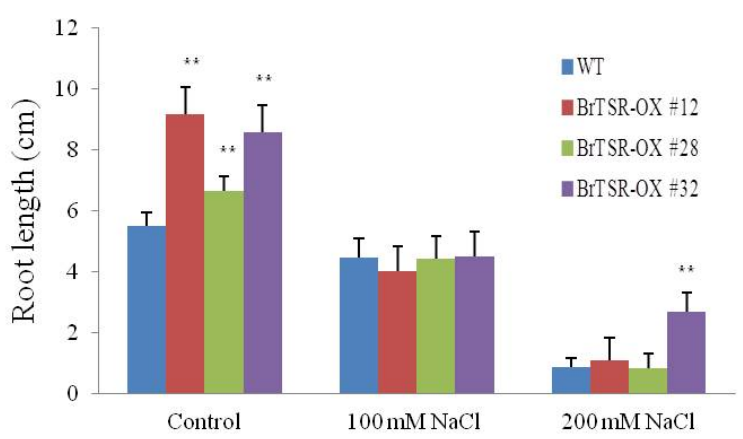

Fig. 4. Response of BrTSR53-OX and wild-type rice to salt stress. (A) Germination rate of BrTSR53-OX transgenic rice after culturing for 14 days. (B) Shoot length of BrTSR53-OX after culturing for 5 days. (C) Shoot length of BrTSR53-OX after culturing for 14 days. (D) Root length of BrTSR53-OX after culturing for 14 days. Error bars represents SD of three replicates. Significant differences depending on $t$-test are indicated by asterisks. ${ }^{*} p<0.05$; ${ }^{* *} p<0.01$. 
the formation of protein aggregates. Over-expressed LEA rice has been generated under various abiotic stresses and its phenotype after being subjected to salt stress for 5 days has been analyzed. In MS media containing $100 \mathrm{mM}$ or 200 $\mathrm{mM} \mathrm{NaCl}$, transgenic lines of $L E A$ rice plants have been found to be more resistant to salt stress than the wild-type rice (Duan et al. 2012). Similar trends were observed for BrTSR53-OX rice plants in this study.

NAC proteins are involved in the regulation of a number of plant growth processes, such as embryo growth, lateral root formation and growth, flower growth, leaf senescence, and secondary wall thickenings (Hu et al. 2008, Zheng et al. 2009 and Song et al. 2011). Over-expressing NAC transcription factor gene can enhance the tolerance of rice to salt stress compared to the wild-type in rice (Hu et al. 2008). These studies have demonstrated that transgenic rice with overexpressed stress-related transcription factor genes are more resistant to salt stress, similar to the findings of this study.

In summary, BrTSR53-OX rice plants were found to be more tolerant to salt stress. Whether BrTSR53-OX confers resistance to other abiotic stresses such as drought and cold stresses merits future study.

\section{ACKNOWLEDGEMENTS}

This study was supported by a grant (Project No. PJ011257) of the Next-Generation Biogreen 21 Program and a grant (Project No.PJ010086) funded by the National Academy of Agricultural Science (NAAS) Agenda, Rural Development Administration, Jeonju, Republic of Korea.

\section{REFERENCES}

Duan J, Cai W. 2012. OsLEA3-2, an abiotic stress induced gene of rice plays a key role in salt and drought tolerance. PLoS One 7: e45117.

Dubouzet JG, Sakuma Y, Ito Y, Kasuga M, Dubouzet EG, Miura S, Seki M, Shinozaki K, Yamaguchi-Shinozaki K. 2003. OsDREB genes in rice, Oryza sativa L., encode transcription activators that function in drought-, high- salt- and cold-responsive gene expression. Plant J. 33: 751-763.

Hiei Y, Ohta S, Komari T, Kumashiro T. 1994. Efficient transformation of rice (Oryza sativa L.) mediated by Agrobacterium and sequence analysis of the boundaries of the T-DNA. Plant J. 6: 271-282.

Hu H, You J, Fang Y, Zhu X, Qi Z, Xiong L. 2008. Characterization of transcription factor gene SNAC2 conferring cold and salt tolerance in rice. Plant Mol. Biol. 67: 169-181.

Kathuria H, Giri J, Tyagi H, Tyagi AK. 2007. Advances in transgenic rice biotechnology. Crit. Rev. Plant Sci. 26: 65-103.

Kim AR, Lim H, Park SH, Ji H, Yoon UH, Kim TH, Cho JI, Kim CK, Lee GS. 2014. Molecular characterization of a putatively stress-related gene BrTSR53 isolated from chinese cabbage (Brassica rapa). Korean J. Breed Sci. 46: 143-51.

Lee SC, Lim MH, Kim JA, Lee SI, Kim JS, Jin M, Kwon SJ, Mun JH, Kim YK, Kim HU, Hur Y, Park BS. 2005. Transcriptome analysis in Brassica rapa under the abiotic stresses using Brassica 24K oligo microarray. Mol. Cells. 26: 595-605.

Livak KJ, Schmittgen TD. 2001. Analysis of relative gene expression data using real-time quantitative PCR and the $2^{-\Delta \Delta C}$ T Method. Methods. 25: 402-408.

Lowe BA, Shiva Prakash N, Way M, Mann MT, Spencer TM, Boddupalli RS. 2009. Enhanced single copy integration events in corn via particle bombardment using low quantities of DNA. Transgenic Res. 18: 831-840.

Martínez-García JF, Monte E, Quail PH. 1999. A simple, rapid and quantitative method for preparing Arabidopsis protein extracts for immunoblot analysis. Plant J. 20: 251-257.

Nakashima K, Tran LS, Van Nguyen D, Fujita M, Maruyama K, Todaka D, Ito Y, Hayashi N, Shinozaki K, YamaguchiShinozaki K. 2007. Functional analysis of a NAC-type transcription factor OsNAC6 involved in abiotic and biotic stress-responsive gene expression in rice. Plant $\mathrm{J}$. 51: 617-630.

Ravikumar G, Manimaran P, Voleti SR, Subrahmanyam D, Sundaram RM, Bansal KC, Viraktamath BC, Balachandran SM. 2014. Stress-inducible expression of AtDREB1A transcription factor greatly improves drought stress tolerance in transgenic indica rice. Transgenic Res. 23: 
421-439.

Song SY, Chen Y, Chen J, Dai XY, Zhang WH. 2011. Physiological mechanisms underlying OsNAC5-dependent tolerance of rice plants to abiotic stress. Planta. 234: 331-345.

Toki S, Hara N, Ono K, Onodera H, Tagiri A, Oka S, Tanaka H. 2006. Early infection of scutellum tissue with Agrobacterium allows high-speed transformation of rice. Plant J. 47: 969-976.

Xiang Y, Tang N, Du H, Ye H, Xiong L. 2008. Characterization of OsbZIP23 as a key player of the basic leucine zipper transcription factor family for conferring abscisic acid sensitivity and salinity and drought tolerance in rice. Plant Physiol. 148: 1938-1952.
Yu L, Chen X, Wang Z, Wang S, Wang Y, Zhu Q, Li S, Xiang C. 2013. Arabidopsis enhanced drought tolerance1/ HOMEODOMAIN GLABROUS11 confers drought tolerance in transgenic rice without yield penalty. Plant Physiol. 162: 1378-1391.

Zhong H, Guo QQ, Chen L, Ren F, Wang QQ, Zheng Y, Li XB. 2012. Two Brassica napus genes encoding NAC transcription factors are involved in response to highsalinity stress. Plant Cell Rep. 31: 1991-2003.

Zheng X, Chen B, Lu G, Han B. 2009. Overexpression of a NAC transcription factor enhances rice drought and salt tolerance. Biochem. Biophys. Res. Commun. 379: 985-989.

Zhu JK. 2001. Plant salt tolerance. Trends Plant Sci. 6: 66-71. 